\title{
Article
}

\section{Biocomposites Composed of Polyamide 11 and Cellulose Nanofibers Pretreated with a Cationic Reagents}

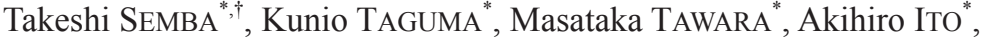 \\ Kazuo KitAGAWA ${ }^{*}$, Akihiro SATO ${ }^{* *}$, and Hiroyuki YANO ${ }^{* * *}$ \\ "Polymer Material Lab., Kyoto Municipal Institute of Industrial Technology and Culture, \\ 91 Chudoji Awata-cho, Shimogyo-ku, Kyoto, Japan \\ ** Chiba Laboratory, New Business Development Division, SEIKO PMC Corporation, \\ 2-3-37 Oonodai, Midori-ku, Chiba, Japan \\ ${ }^{* * * *}$ Research Institute for Sustainable Humanosphere, Kyoto University \\ Gokashou, Uji, Kyoto, Japan \\ (Received : October 19, 2016)
}

\begin{abstract}
Cellulose nanofibers (CNFs) have many useful properties, including high strength and low thermal expansion. They are environmentally friendly, renewable, safe, and biodegradable. The focus of this study was to develop lightweight thermoplastic polymer composites with good mechanical properties by incorporating CNFs pretreated with a cationic reagent. Polyamide 11 (PA11) was mixed with the surface-treated CNFs using a twin-screw extruder and the resulting pellets were injection molded. Four different cationic reagents were used to modify the hydroxyl groups on the CNF surface, which resulted in better dispersion of the CNFs in the composites owing to reduced hydrogen bonding between the CNFs. The best cationic reagent for the preparation of CNF-reinforced composites was poly (N-methyl diallyl amine)-epichlorohydrin. The polymer consisted of repeating cationic quaternary ammonium salt units and was grafted with epichlorohydrin, which contained a reactive epoxy group. The molten viscosity of the composite prepared using poly (N-methyl diallyl amine)-epichlorohydrin was the highest of all the prepared composites. The high viscosity was attributed to the dispersed state of the CNFs in the composites and interfacial interactions between CNF and the PA11 matrix. The mechanical properties, fracture aspect, and thermal properties of the composites were strongly related to the molten viscosity. Cationic pretreatment of the surface of the CNFs enhanced the dispersion of the fibers and significantly improved the mechanical and thermal properties of the composites.
\end{abstract}

Key Words: Cellulose nanofiber / Cationic treatment / Mechanical property / Molten viscosity / Heat distortion temperature

\section{INTRODUCTION}

Cellulose nanofibers (CNFs) have various morphologies including cellulose microfibrils, which have a diameter of $4 \mathrm{~nm}$ and consist of 36 cellulose molecules arranged in a 6 by 6 array, a bundle of cellulose microfibrils, and microfibrillated cellulose, which resembles a spider's web and consist of cellulose microfibrils with diameters of several hundreds of nanometer. ${ }^{1)}$ CNFs have diverse and fascinating features, such as high strength, which is five times the strength of steel and the same strength as aramid fibers ${ }^{2,3}$, and low thermal expansion similar to quartz glass. ${ }^{4)}$ Cellulose is the main component of the cell wall of plants. It is the most abundant organic compound in the natural world, and it is produced by photosynthesis in plants from carbon dioxide and water. CNFs

$\dagger$ Corresponding author

sentake@tc-kyoto.or.jp and its polymer composite materials can be used to obtain green composites with high mechanical properties.

The advantage of CNFs compared with other fibers used for the reinforcement of polymers, such as glass fiber (GF) and carbon fiber (CF), is their low density and the resulting smooth surfaces in the polymer composites. The densities of CNFs, GFs, and CFs are $1.5 \mathrm{~g} / \mathrm{cm}^{3}, 2.5 \mathrm{~g} / \mathrm{cm}^{3}$, and $1.8 \mathrm{~g} / \mathrm{cm}^{3}$, respectively. In our previous study, CNF-reinforced Polyamide 6 composites with a CNF loading of $10 \mathrm{wt} \%$ had a better modulus and strength than GF-reinforced composites with a GF loading of $20 \mathrm{wt} \%{ }^{5)}$ The reduction of weight is very effective for saving energy in the transportation industry. It has been determined that a $10 \%$ reduction in weight results in approximately $10 \%$ better fuel efficiency in cars. ${ }^{6}$ Furthermore, the fine nanomorphology of CNFs can remove the unevenness formed on the surface of polymer composite products reinforced by macro- and microsized fibers.

Although CNFs have a lot of attractive features, there are 
some problems that must be overcome during nanofibrillation and their combination with polymers. Cellulose molecules aggregate to form CNFs with a complex and strong structure in the cell wall of the plant, which is held together by strong intermolecular hydrogen bonding. The techniques used to break down the higher order structures of CNFs can be broadly divided into mechanical and chemical methods. Mechanical methods include the use of high-pressure homogenizers ${ }^{7,8)}$, microfluidizers ${ }^{9)}$, ball mills ${ }^{10)}$, grinders ${ }^{11)}$ and twin-screw extruders, whereas chemical methods include oxidation using 2,2,6,6-tetramethylpiperidine-1-oxyl $\left(\right.$ TEMPO) ${ }^{12,13)}$ and ionic liquid dissolution methods. ${ }^{14)}$

Biopolymers made from plants or bacteria have also received as much attention as CNFs. The most common biopolymer in practical use is polylactic acid. ${ }^{15,16)}$ However, bio-polyethylene and bio-polypropylene ${ }^{17)}$ have not been able to replace polymers derived from petroleum. It is often assumed that biopolymers have only been commercialized in recent years. However, polyamide 11 (PA11), which is produced from ricinus castor oil, has been used in the automotive industry for fuel tubes and pneumatic brake tubes for 20 years. In this study, we developed CNF-reinforced PA11 composites that maintain the useful properties of PA11 such as chemical resistance, tribology, and cold-impact resistance, and improve its heat resistance modulus and strength. The composites were prepared from biomaterials, and the aggregation of the CNFs was restrained by surface modification using appropriate cationic reagents. ${ }^{18)}$

\section{MATERIAL AND METHOD}

\subsection{Materials and Preparation}

\subsubsection{Morphology of CNFs}

CNF was purchased from Daicel Chemical Industries, Ltd., Osaka, Japan. The morphology of freeze-dried CNF is shown in Figure 1. A fine fibrillated structure can be seen, ranging in size from tens of nanometers to several micrometers. The presence of these fine structures usually leads to agglomeration when the material is mixed with a polymer; therefore, pretreatment of the surface of the filler is often useful to minimize the agglomeration.

\subsubsection{Surface modification of CNFs}

The treatment of the CNF surface with positively charged cationic reagents is considered particularly useful because the cellulose surface has a negative charge in a water. Therefore, cationic reagents have been employed for the surface treatment of CNFs. Treatment with a cationic compound is also predicted to prevent the agglomeration of CNFs during mixing with a polymeric matrix because it prevents the hydrogen bonding between the CNFs. Four types of cationic surface treatment compounds were employed (Figure 2), which were kindly supplied by Seiko PMC Corporation, Tokyo, Japan and Senka Corporation, Osaka, Japan. The first compound was a reactive quaternary ammonium salt monomer bearing an epoxy group that can covalently link with hydroxyl groups of CNFs. The second compound was a reactive polymer (1) consisting of repeating quaternary ammonium salt units and grafted with epichlorohydrin, which has a reactive epoxy group. It has a molecular weight of approximately $40000 \mathrm{~g} / \mathrm{mol}$. The third compound was a reactive polymer (2) consisting of repeating amide bonds and grafted with reactive azetidinium ring. It has a molecular weight above $10000 \mathrm{~g} / \mathrm{mol}$. The final compound was a nonreactive (adsorption-type) consisting of alternating quaternary ammonium salt units and secondary ammonium salt units. It has a molecular weight above $100000 \mathrm{~g} / \mathrm{mol}$. The compositions of the reaction solution are listed in Table I. The reaction procedures were as follows.

(a) Reactive type monomer: A dispersion of CNFs (60 g) in $2 \mathrm{~L}$ of pure water and a solution of sodium hydroxide $(33 \mathrm{~g})$ in $1 \mathrm{~L}$ of pure water were mixed at $80^{\circ} \mathrm{C}$. The reactive type monomer of $300 \mathrm{phr}$ for the CNF was added to the
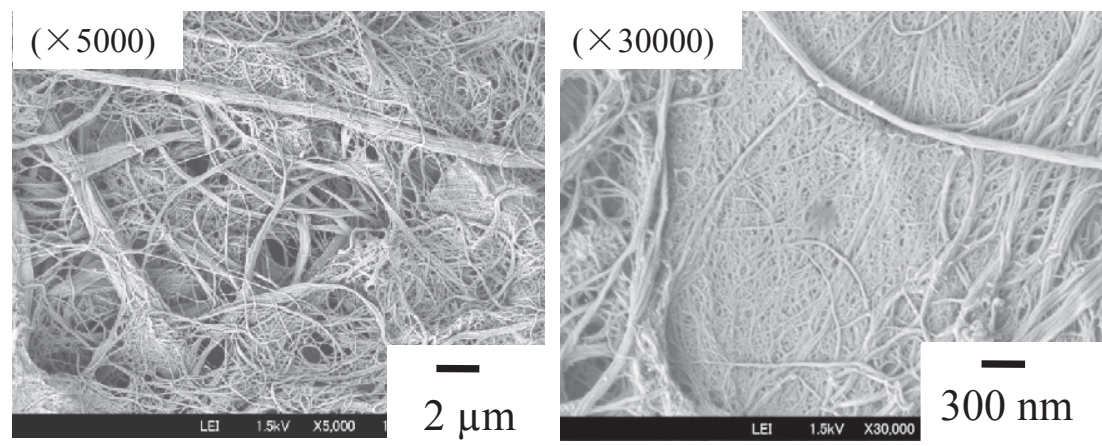

Fig. 1. Morphology of freeze dried CNFs. 
agitated CNF slurry, and the mixture was kept at $80{ }^{\circ} \mathrm{C}$ for $60 \mathrm{~min}$. Finally, the reaction mixture was neutralized with hydrochloric acid and rinsed with pure water.

(b) Reactive type polymer (1), (c) Reactive type polymer (2), (d) nonreactive (adsorption) type polymer: These three polymers were reacted with the CNF using the same procedure. A dispersion of CNFs $(60 \mathrm{~g})$ and one of the three polymers were mixed in $2 \mathrm{~L}$ of pure water. Sodium hydroxide $(90 \mathrm{~g})$ was dissolved in $1 \mathrm{~L}$ of pure water. The CNF slurry and the alkaline solution were mixed at $40{ }^{\circ} \mathrm{C}$ for $60 \mathrm{~min}$. Finally, the reaction mixture was neutralized with hydrochloric acid and rinsed with pure water.

The four reagents had a different affinity to CNF, which depended on factors such as their molecular weight, the type of binding (covalent bonding or adsorption) to the CNFs, the reactivity of the functional groups, and steric hindrance. Therefore, the amount of reagent that reacted and or adsorbed on the CNF was different. Elemental analysis using a total nitrogen analyzer (TN-110, Mitsubishi Chemical Analytech Co., Ltd. Chigasaki, Japan) was performed because all the reagents contained nitrogen.

\subsubsection{PA11 matrix}

The thermoplastic polymer used as the matrix material in this study was PA11 in both pellet and powder form, which was kindly supplied by Arkema K.K., Colombes, France. PA11 is polycondensed by opening the ring of the undecane lactam derived from ricinus castor oil. Therefore, the resulting CNF composites are all derived from biomaterials. The general properties of the PA11 materials are shown in Table II. The PA11 powder had an average particle size of $30 \mu \mathrm{m}$. The solution viscosity of $0.5 \mathrm{wt} \%$ solution was measured at $20{ }^{\circ} \mathrm{C}$ in metacresol by means of an Ubbelohde's viscometer. The viscosity of the pellets was higher than that of the powder owing to a higher molecular weight and/or more branching in the pelletized polymer. In general, because of its high polarity, PA shows good compatibility with many types of fillers (a) Reactive type monomer<smiles>C[N+](C)(C)CC1CO1</smiles>

(c) Reactive type polymer (2)<smiles>CC(C)(C)NCC[N+]1(CCNC(=O)CCCCC(=O)C(F)(F)F)CC(O)C1</smiles>

(b) Reactive type polymer (1)<smiles>CCCC1C[N+](C)(CC(O)CCl)CC1CC</smiles>

(d) Nonreactive (adsorption) type polymer

Table I. Compositions of the reaction solutions.

\begin{tabular}{|l|c|c|c|c|c|c|}
\hline \multirow{2}{*}{ Symbol and name of reactive compound } & \multicolumn{3}{|c|}{ Amounts } & \multicolumn{2}{c|}{ Temperature and time } \\
\cline { 2 - 8 } & Reactive compound & CNF & Sodium hydroxide & Pure water & Temperature & Rexction time \\
\cline { 2 - 8 } & $\mathrm{g}$ & $\mathrm{g}$ & $\mathrm{g}$ & $\mathrm{ml}$ & ${ }^{\circ} \mathrm{C}$ & $\mathrm{min}$ \\
\hline (a) Reactive type monomer & 180 & 60 & 33 & 3000 & 80 & 60 \\
\hline (b) Reactive type polymer (1) & 18 & 60 & 90 & 3000 & 40 & 60 \\
\hline (c) Reactive type polymer (2) & 18 & 60 & 90 & 3000 & 40 & 60 \\
\hline (d) Nonreactive (adsorption) type polymer & 18 & 60 & 90 & 3000 & 40 & 60 \\
\hline
\end{tabular}

Table II. General properties of the PA11 materials.

\begin{tabular}{|c|c|c|c|c|c|}
\hline Appearance & $\begin{array}{l}\text { Average } \\
\text { size }\end{array}$ & $\begin{array}{c}\text { Melting point } \\
\left({ }^{\circ} \mathrm{C}\right)\end{array}$ & \begin{tabular}{|c|} 
Glass \\
transition point \\
$\left({ }^{\circ} \mathrm{C}\right)$ \\
\end{tabular} & $\begin{array}{l}\text { Specific } \\
\text { gravity }\end{array}$ & $\begin{array}{l}\text { Inherent solution } \\
\text { viscosity (-) }\end{array}$ \\
\hline Powder & $30 \mu \mathrm{m}$ & \multirow{2}{*}{187} & \multirow{2}{*}{37} & \multirow{2}{*}{1.04} & $0.70-1.00$ \\
\hline Pellet & $2-4 \mathrm{~mm}$ & & & & $1.35-1.55$ \\
\hline
\end{tabular}


based on finely ground or as-synthesized nanosized minerals. Therefore, it is reasonable to investigate the combination of CNF and PA to assess the feasibility of thermoplastic polymer composites that incorporate CNFs. The use of PA11 for this purpose presents some advantages because its melting point and processing temperature are significantly lower than those of PA6 and PA66, thus avoiding the high processing temperatures that often cause thermal degradation and lower the performance of cellulose-based materials. Furthermore, the water absorptivity and cold-resistant impulsiveness are superior to PA6 and PA66.

\subsection{Compounding and Fabrication of the Specimens}

During processing, equal weights of PA11 powder and CNF were mixed in water, stirred, and then filtered. The addition of PA11 powder to the CNF in this manner was intended to prevent agglomeration of the CNF. The resulting mixtures containing $50 \mathrm{wt} \% \mathrm{CNF}$ and $50 \mathrm{wt} \%$ PA11 were dried and ground to a powder and subsequently compounded with PA11 pellets using a twin extruder. A summary of the various sample specimens that were produced is given in Table III. The material without CNF (PA11 pellets/PA11 powder $=80 / 10$ ) as control material was also prepared by melt compound method.

Thus, CNFs with and without surface treatment were first combined with PA11 powder and then were compounded with PA11 pellets by melting using a twin-screw extruder (screw diameter $=15 \mathrm{~mm}$, screw length $/$ diameter $=45$, ZSK 60, Technovel Corp., Osaka, Japan), to dilute the cellulose content. The temperature gradient of the cylinder from the feeding zone to the die was from 170 to $190^{\circ} \mathrm{C}$, and the screw revolution rate was $250 \mathrm{rpm}$. The final composition of the product was PA11-pellets/PA11-powder/CNF $=80 / 10 / 10$ by weight. The dilution of high viscosity resins such as PA11 pellets empirically improves the dispersion state owing to better shear stress transfer from the screw tip and extruder wall to the dispersed fillers. ${ }^{19)}$ Molded specimens of the compounded materials were produced using a cylinder temperature gradient from the feeding zone to the injection nozzle from 180 to $210^{\circ} \mathrm{C}$, and a cavity temperature of $35^{\circ} \mathrm{C}$ by using an injection molding machine (NPX-7; Nissei Plastic Industrial Co., Ltd., Hanisina, Japan). Bar-shaped specimens ( $4 \mathrm{~mm}$ thick) were fabricated for bending tests, Izod impact test, and heat distortion temperature test.

\subsection{Molten Viscosity of CNF/PA11 Composites}

Molten viscosity is deeply related to the dispersion state of the filler in the matrix and the interfacial interaction between the filler and the matrix. In this case, the well-dispersed state of the CNFs and the firm interfacial interaction of $\mathrm{CNF} / \mathrm{PA} 11$ led to higher viscosity. Moreover, to assess the processability of the polymer materials using various polymer processing methods such as extrusion and compression, it was necessary to measure the viscosity throughout a wide range of shear rates. Therefore, a superposition of two viscosity measurements obtained using a capillary rheometer (Capirograph ID; Toyo Seiki Seisaku-sho Ltd. Tokyo, Japan) and a parallel plate rheometer (ARES; TA Instruments, Newcastle, Delaware, USA) was applied. This method was used to obtain viscosity measurements in a wide range of shear rates $\left(10^{-2}-10^{3} \mathrm{sec}^{-1}\right)$ at $200{ }^{\circ} \mathrm{C}$ as the reference temperature.

\subsection{Bending and Izod Impact Tests}

Bending tests of bar-type 4-mm-thick specimens were carried out using a universal testing machine (Autograph AG-5000E; Shimadzu Corp., Kyoto, Japan) at a bending rate of $10 \mathrm{~mm} / \mathrm{min}$ and using a 64-mm span length at room temperature. Two types of Izod impact tests were performed on bar-type injection-molded specimens. One test was the normal Izod impact test using a $2.75 \mathrm{~J}$ hammer $(2.75 \mathrm{~J}-\mathrm{N})$, in which the crack propagated from the tip of the notch after

Table III. Compositions of the CNF/PA11 composites.

\begin{tabular}{|c|c|c|c|c|c|c|c|c|c|}
\hline \multirow[b]{2}{*}{ Number } & \multirow{2}{*}{$\begin{array}{c}\text { Abbreviated } \\
\text { designation }\end{array}$} & \multicolumn{7}{|c|}{ Matereial content (wt $\%)$} & \multirow{3}{*}{$\begin{array}{l}\mathrm{wt} \% \text { of cationic } \\
\text { regent on } \mathrm{CNF}\end{array}$} \\
\hline & & $\begin{array}{l}\text { PA11 } \\
\text { pellet }\end{array}$ & $\begin{array}{c}\text { PA11 } \\
\text { powder }\end{array}$ & $\begin{array}{c}\text { No treated } \\
\text { CNF }\end{array}$ & Cationic CNF[I] & $\begin{array}{l}\text { Cationic } \\
\mathrm{CNF}[\mathrm{II}]\end{array}$ & $\begin{array}{l}\text { Cationic } \\
\text { CNF[III] }\end{array}$ & Cationic CNF[IV] & \\
\hline \multicolumn{2}{|c|}{ Surface treatment compound } & - & - & - & $\begin{array}{c}\text { (a) Reactive type } \\
\text { monomer }\end{array}$ & $\begin{array}{c}\text { (b)Reactive type } \\
\text { polymer (1) }\end{array}$ & \begin{tabular}{|c|} 
(c)Reactive type \\
polymer (2)
\end{tabular} & \begin{tabular}{|c|} 
(d)Nonreactive \\
(adsorption) type polymer
\end{tabular} & \\
\hline 1 & PA11 neat & 88.9 & 11.1 & 0 & 0 & 0 & 0 & 0 & - \\
\hline 2 & PA11/CNF & \multirow{5}{*}{80} & \multirow{5}{*}{10} & 10 & 0 & 0 & 0 & 0 & 0 \\
\hline 3 & PA11/CNF[I] & & & 0 & 10 & 0 & 0 & 0 & 2.5 \\
\hline 4 & PA11/CNF[II] & & & 0 & 0 & 10 & 0 & 0 & 7.7 \\
\hline 5 & PA11/CNF[III] & & & 0 & 0 & 0 & 10 & 0 & 0.6 \\
\hline 6 & PA11/CNF[IV] & & & 0 & 0 & 0 & 0 & 10 & 1.4 \\
\hline
\end{tabular}


striking of the notch side. The second was a reverse Izod impact test using a $5.5 \mathrm{~J}$ hammer $(5.5 \mathrm{~J}-\mathrm{R})$ in which the crack propagated from the opposite side of the notch after striking of the opposite side. The former method evaluates the impact strength, taking into account notch sensitivity, whereas the latter method evaluates the strength of the specimens without the presence of a crack. The fracture surfaces produced by these tests were studied with a field emission scanning electron microscope (FE-SEM: JSM6700; JEOL, Tokyo, Japan).

\subsection{Heat Distortion Temperature Tests}

Bar-type 4-mm-thick specimens were also used for heat distortion temperature (HDT) tests. The HDT values were measured when the distortion displacement of the samples reached $0.34 \mathrm{~mm}$ at an applied load of either 0.45 or $1.8 \mathrm{MPa}$ and a heating rate of $2{ }^{\circ} \mathrm{C} / \mathrm{min}$.

\subsection{Observation of Dispersed Cellulose Fiber in the Matrix and Fracture Aspect}

$\mathrm{X}$-ray computed tomography (XCT) has rapidly progressed as an analytical tool and is currently applied not only in medicine but also in various engineering disciplines because it can provide precise three-dimensional (3D) images of internal structures. The resolution of the XCT apparatus (SKY Scan 1172: Bruker-micro CT, Kontich, Belgium) used in this study was $1.3 \mu \mathrm{m}$. Each injection-molded specimen was scanned and 3D images were constructed to evaluate the dispersion state of the cellulose fibers. A resolution of $1.3 \mu \mathrm{m}$ is insufficient to allow a detailed evaluation of the nanocomposite materials, but the 3D images do offer useful information about agglomeration and aggregation of cellulose fibers in the PA11/CNF composites.

The fracture aspects of Izod impact test were observed using FE-SEM. The captured areas were next to the notch area and the center of the fracture surface, in which the unstable crack propagation is dominant near the notch, and the stable crack propagation is dominant in the center of the fracture surface area.

\section{RESULTS AND DISCUSSION}

\subsection{Reacting and/or Adsorption Weight of Cationic Regent on CNF}

The weight percentage of cationic reagent that reacted with and/or adsorbed on the CNFs is shown in Table III. The weight gain was very different depending on the type of cationic reagent. A weight gain of only 0.6 and $1.4 \mathrm{wt} \%$ was observed for (c) reactive type polymer (2) and (d) nonreactive (adsorption) type polymer, implies insufficient electrostatic attraction to CNF as a result of their low cationic character, i.e., the frequency of quaternary ammonium salt units bearing cations in its repeating unit is less than (a) reactive type monomer and (b) reactive type polymer (1), as shown in Figure 2. The number of reactive azetidinium ring units was also insufficient in reactive type polymer (2). In the case of (a) reactive type monomer, all monomers possess a positive charge and a reactive epoxy unit, and the gain of weight of $2.5 \mathrm{wt} \%$ was relatively high, even though its molecular weight is quite small. The (b) reactive type polymer (1) exhibited the highest gain of $7.7 \mathrm{wt} \%$. From these results, a large number of cationic units and a moiety that can form covalent bonds in the reagent is favorable for increasing the weight percentage of the reagent on the CNF. The difference in weight gain on the $\mathrm{CNF}$ between (a) reactive type monomer (2.5 wt $\%$ ) and (b) reactive type polymer (1) $(7.7 \mathrm{wt} \%)$ is attributed to the difference in the molecular weight of each compound.

\subsection{Molten Viscosity of CNF/PA11 Composites}

The shear rate range of each composite (Figure 3) was different owing to the sensitivity limitation of the parallel plate rheometer. The viscosity drop from the zero shear viscosity area to the higher shear rate area in the PA11 curve was partly owing to the isotropy of the PA11 polymer. In the case of all the CNF/PA11 composites, the viscosities were increased after the incorporation of $\mathrm{CNF}$, and the tendency of the structural viscosity was observed, i.e., the viscosities suddenly decreased with increasing shear rate without Newtonian region. The three composites that incorporated positively charged $\mathrm{CNF}$ had a lower viscosity than the composites reinforced with nontreated CNF. However, the composite that incorporated CNF with (b) reactive type polymer (1) only exceeded the composites with the incorporation of nontreated CNF. We

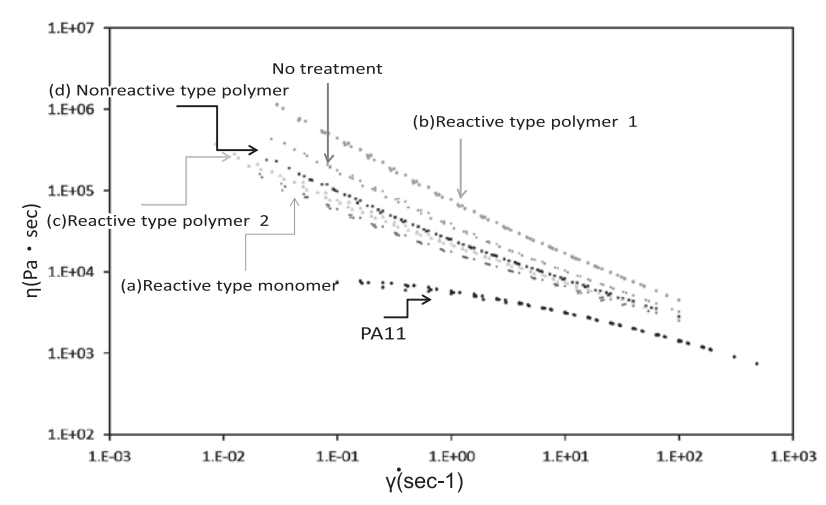

Fig. 3. The viscosity of CNF/PA11 composites obtained after various surface treatments. 
proposed that the cationic regions in the treated composites were apart from the CNF surface as a result of strong flow stress and high temperature during the twin-screw mixing and injection molding processes, after which the released reagents behaved as a plasticizer. On the contrary, (b) the reactive type polymer (1) bound on the CNF strongly via covalent bonding and/or cationic adsorption, so a viscosity drop was not generated. This high viscosity trend can be expected thereby high dispersibility and interface adhesion of CNF/PA11.

\subsection{Bending and Izod Impact Tests}

Figure 4 shows the stress-strain curves resulting from the bending tests. The ductile nature of the PA11 matrix was maintained in all the composites despite the incorporation of $10 \mathrm{wt} \%$ rigid CNF. This indicated that the CNF used in this study has some degree of compatibility with the PA11 matrix, and the interfacial adhesion is relatively good. The bending modulus and strength increased after the addition of CNFs in PA11. However, the bending modulus and strength of the three composites that were reinforced by positively charged CNFs treated by (d) nonreactive polymer, (c) reactive type polymer (2) and (a) reactive monomer were equal to that of the nontreated CNF reinforced composites, as shown in Table IV. In contrast, composites containing CNF treated by (b) reactive type polymer (1) exhibited excellent bending properties. This result is in agreement with the viscometry results and was attributed to the high dispersibility and/or the interface adhesion in the composites after the loading of the CNF treated by (b) reactive type polymer (1).

Izod impact test results are also given in Table IV. Neat PA11 polymer showed the highest impact strength in both the 2.75J-N and 5.5J-R tests. CNF reinforcement decreased the impact strength of the composites. The composites that incorporated (b) reactive type polymer (1) showed the smallest reduction in impact strength. Therefore, the impact strength results also agree with the viscometry results.

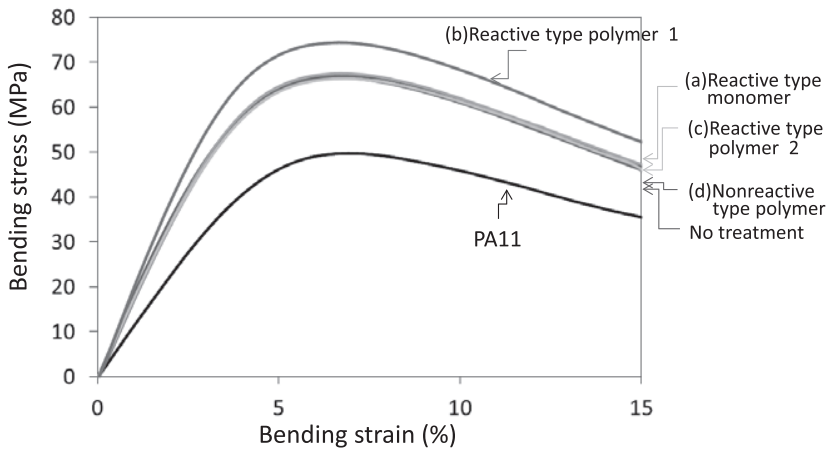

Fig. 4. Stress-strain curves resulting from bending tests.

Table IV. Bending and Izod impact test results for the CNF/PA11 composites.

\begin{tabular}{|c|l|c|c|c|c|c|}
\cline { 4 - 7 } Number & \multirow{2}{*}{\begin{tabular}{c} 
Abbreviated designation \\
\cline { 4 - 7 }
\end{tabular}} & Cationic agents & $\begin{array}{c}\text { Bodulus } \\
(\mathrm{MPa})\end{array}$ & $\begin{array}{c}\text { Strength } \\
(\mathrm{MPa})\end{array}$ & $2.75 \mathrm{~J}-\mathrm{N}$ & $5.5 \mathrm{~J}-\mathrm{R}$ \\
\hline 1 & PA11 neat & - & 1160 & 49.6 & 8.04 & $\mathrm{NB}$ \\
\hline 2 & PA11/CNF & - & 1890 & 67.4 & 3.88 & 54.8 \\
\hline 3 & PA11/CNF[I] & (a)Reactive type monomer & 1780 & 66.6 & 4.27 & 43.5 \\
\hline 4 & PA11/CNF[I] & (b)Reactive type polymer (1) & 2060 & 72.7 & 4.58 & 80.7 \\
\hline 5 & PA11/CNF[II] & (c)Reactive type polymer (2) & 1830 & 67.7 & 3.93 & 58.9 \\
\hline 6 & PA11/CNF[IV] & (d)Nonreactive (adsorption) type polymer & 1780 & 65.8 & 3.62 & 51.1 \\
\hline
\end{tabular}

NB: no break
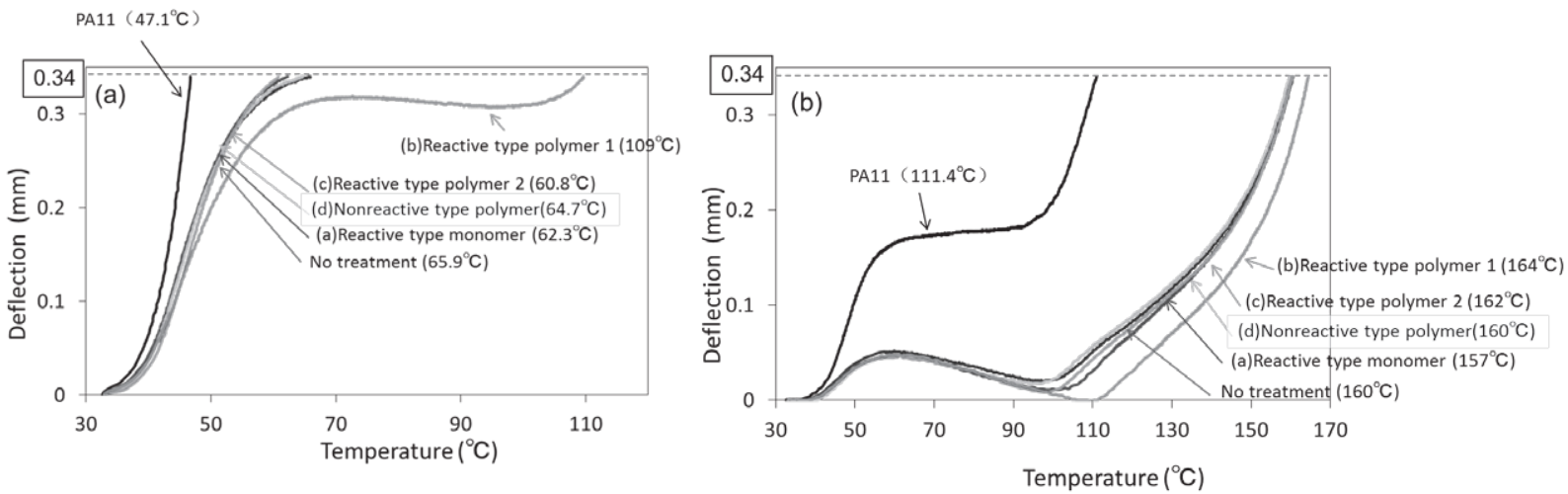

Fig. 5. Heat distortion curves under a loading of (a) $0.45 \mathrm{MPa}$ and (b) $1.80 \mathrm{Mpa}$. The HDT value is expressed in parenthesis. 


\subsection{Heat Distortion Temperature}

The HDT curves obtained under loads of 0.45 and $1.80 \mathrm{MPa}$ are shown in Figure 5 (a) and (b). In the case of $0.45 \mathrm{MPa}$ loading, the composites incorporating (b) reactive type polymer (1) exhibited the highest HDT of $109^{\circ} \mathrm{C}$, in which the increment from neat PA 11 was $52^{\circ} \mathrm{C}$. However, the other composites reinforced by modified CNF treated by (d) nonreactive polymer, (c) reactive type polymer (2) and (a) reactive monomer were slightly lower than that of the nontreated CNF reinforced composites. The trend of the HDT obtained under a loading of $1.80 \mathrm{MPa}$ was almost the same as $0.45 \mathrm{MPa}$ loading. However, the shape of each HDT curve was different because of the use of a heavier weight. The HDT properties also agree with the viscometry results.

\subsection{Observation of Dispersed Cellulose Fiber in Matrix and Fracture Aspect}

The images of dispersed cellulose in the composites were obtained using an XCT apparatus, as shown in Figure 6. The white dot, fibril, and cluster indicates cellulose dispersions of more than $1.3 \mu \mathrm{m}$ resolution in cubes of $1 \mathrm{~mm}$. The fine cellulose less than $1.3 \mu \mathrm{m}$ would be dispersed in the dark area. The dispersion of CNFs in each sample was quite different. The largest agglomerated clusters were observed in the composites containing CNF modified with (a) reactive monomer, in which the maximum size of the cluster was about $300 \mu \mathrm{m}$. The agglomerated clusters of the composites containing CNF modified with (d) nonreactive type polymer were approximately $200 \mu \mathrm{m}$. The dispersion of cellulose in the composites modified by (b) reactive type polymer(1) and (c) reactive type polymer (2) were similar, in which the maximum size of the clusters was less than $100 \mu \mathrm{m}$. The XCT results indicate that the two types of reactive type polymers yielded fine cellulose dispersions.

The fracture properties of the composites are shown in Figure 7. The tendency of the fracture properties was the same in both observation areas, next to the notch and the center of the fracture surface. Nonfibrillated or agglomerated large fibers larger than a few micrometers were evident on the fracture surfaces of the nontreated, (a) reactive type monomer, (d) nonreactive type polymer composites, as marked by a dotted circle. The revealed large fibers indicated smooth surface and pulled out from matrix PA6. It is evidence of no friction and interaction between the fiber and the matrix. Conversely, the dispersed fibers in the composites incorporating (b) reactive type polymer (1) and (c) reactive type polymer (2) were less than a few hundred nanometers, in which the large fibers observed in the XCT images would be buried in the PA6 matrix, resulting in good interfacial interaction between the
PA11

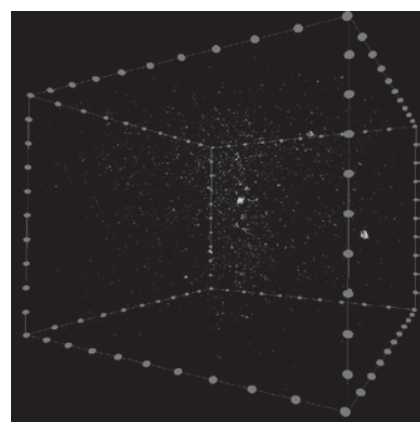

(b)Reactive type polymer 1

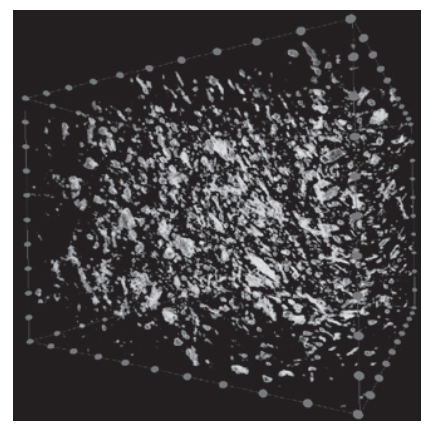

No treatment

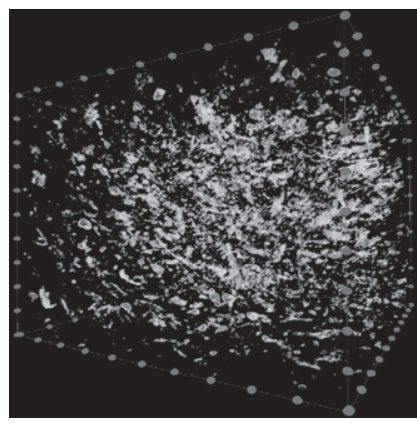

(c)Reactive type polymer 2

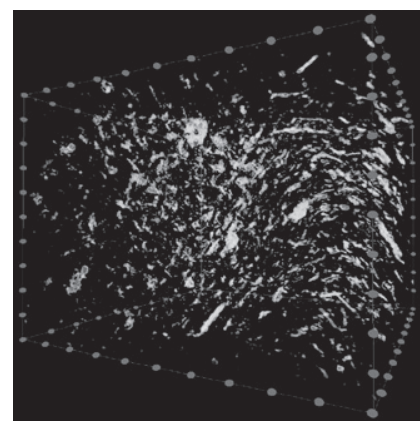

(a)Reactive type monomer

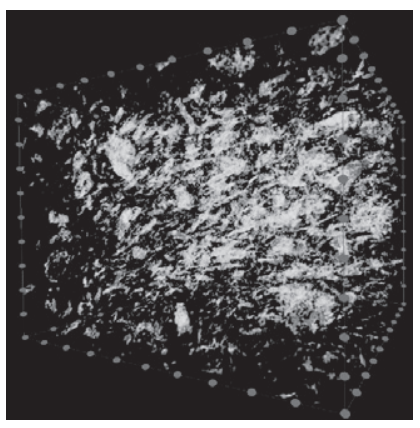

(d)Nonreactive type polymer

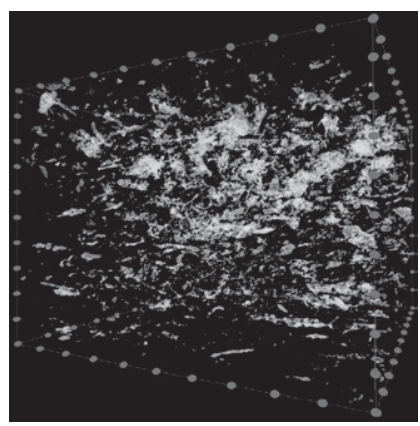

Fig. 6. XCT images of dispersed cellulose in the composites. 
fiber and matrix. Thus, the dispersed state and interfacial interaction of the composites were reflected in the mechanical, thermal, and rheological properties.

\section{CONCLUSION}

Cellulose nanofibers (CNFs) pretreated with cationic reagents were used to form PA11 polymer composites with good dispersion of CNF and improved interfacial interaction between the CNFs and PA11. The main results of this study were as follows:

- The presence of more cations, epoxy units, and the higher molecular weight of the reagents was favorable for increasing the weight of cationic compound on the CNFs. The cations promote frequency to access the CNF surface, and then the reactive epoxy units form covalent bonds with the hydroxyl groups on the CNF surface.
The capping of the hydroxyl groups with long molecular chain cationic compounds prevents hydrogen bonding and creates steric hindrance between the CNFs. Furthermore, the repulsion between the cations is favorable for mixing of PA11 powder and CNF in water.

- The molten viscosity could be used to predict the properties of the composites. The composites with a high molten viscosity exhibited good mechanical and thermal properties, had well-dispersed CNFs, and excellent interfacial interaction between the CNF and PA11.

- The bending modulus, strength, and HDT were improved by treating the CNF with cationic compounds. In particular, the HDT value under a loading of 1.8 MPa was $62{ }^{\circ} \mathrm{C}$ higher than that of pure PA11.

- The XCT images and the fractured surface showed the dispersed state of CNF and the interfacial interaction between CNF and PA11.

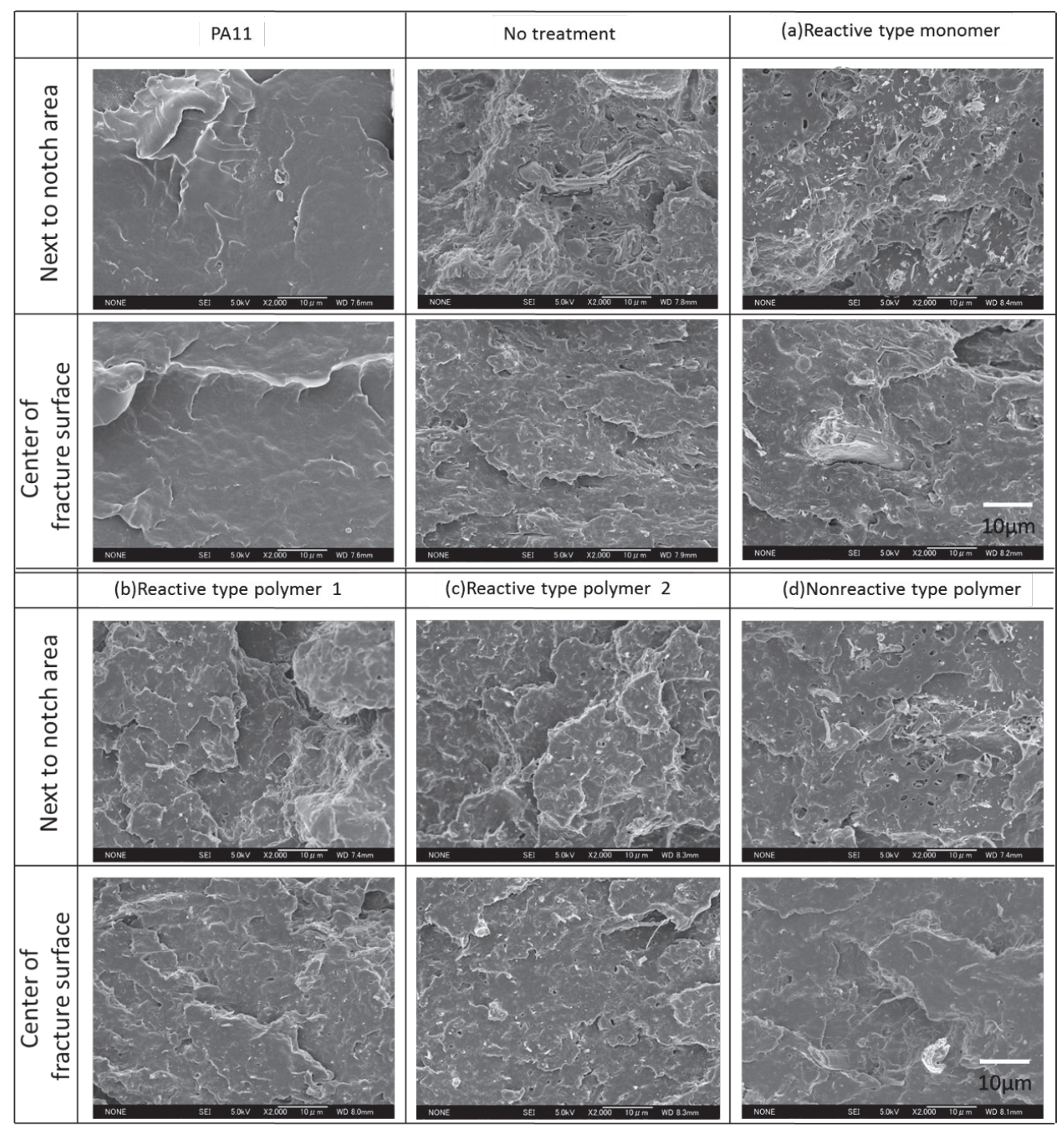

Fig. 7. Fracture surface of each sample next to the notch area and center of the fracture surface. 


\section{REFERENCES}

1) Abe K, Iwamoto S, Yano H, Obtaining cellulose nanofibers with a uniform width of $15 \mathrm{~nm}$ from wood, Biomacromolecules, 8, 3276-3278 (2007).

2) Page $\mathrm{DH}, \mathrm{El}-\mathrm{Hosseiny} \mathrm{F}$, The mechanical properties of single wood pulp fibres, J Pulp Pap Sc, 9, 99-100 (1983).

3) Saito T, Kuramae R, Wohlert J, Berglund LA, Isogai A, The Strength of Single Cellulose Nanofibrils Revealed via SonicationInduced Fragmentation, Biomacromolecules, 14, 248-253 (2013).

4) Nishino T, Matsuda I, Hirao K, All-Cellulose Composite, Macromolecules, 37, 7683-7687 (2004).

5) Semba T, Taguma K, Tawara M, Nishioka S, Ito A, Kitagawa K, Kataoka H, Yano H, Nakatsubo F, Thermoplastic Composites Reinforced by Cellulose Nano-fiber Induced from Shear Flow in Polymer Compounding Process, 14th Japan International SAMPE Symposium in Kanazawa, December 6-9 (2015).

6) Miller WS, Zhuang L, Bottema J, Wittebrood A, De-Smet $\mathrm{P}$, Haszler A, Vieregge A, Recent development in aluminium alloys for the automotive industry, Materials Sci and Engineering A, 280, 37-49 (2000).

7) Pääkkö M, Ankerfors M, Kosonen H, Nykänen A, Ahola S, Österberg M, Lindström T, Enzymatic hydrolysis combined with mechanical shearing and high-pressure homogenization for nanoscale cellulose fibrils and strong gels, Biomacromolecules, 8, 1934-1941 (2007).

8) Nakagaito AN, Yano. H, Novel high-strength biocomposites based on microfibrillated cellulose having nano-order-unit weblike network structure, Applied Physics A, 80, 155-159 (2005).

9) Ferrer A, Filpponen I, Rodríguez A, Laine J, Rojas OJ, Valorization of residual Empty Palm Fruit Bunch Fibers (EPFBF) by microfluidization: production of nanofibrillated cellulose and EPFBF nanopaper, Bioresource Technology, 125, 249-255 (2012).
10) Qua EH, Hornsby PR, Sharma HS, Lyons G, McCall RD, Preparation and characterization of poly (vinyl alcohol) nanocomposites made from cellulose nanofibers, $J$ of Applied Polymer Science, 113, 2238-2247 (2009).

11) Iwamoto S, Nakagaito AN, Yano H, Nano-fibrillation of pulp fibers for the processing of transparent nanocomposites, Applied Physics A, 89, 461-466 (2007).

12) Isogai A, Saito T, Fukuzumi H, TEMPO-oxidized cellulose nanofibers, Nanoscale, 3, 71-85 (2011).

13) Saito T, Kimura S, Nishiyama Y, Isogai A, Cellulose nanofibers prepared by TEMPO-mediated oxidation of native cellulose, Biomacromolecules, 8, 2485-2491 (2007).

14) Zhang $\mathrm{H}, \mathrm{Wu}$ J, Zhang J, He J, 1-Allyl-3-methylimidazolium chloride room temperature ionic liquid: a new and powerful nonderivatizing solvent for cellulose, Macromolecules, $\mathbf{3 8}$, 8272-8277 (2005).

15) Lunt J, Large-scale production, properties and commercial applications of polylactic acid polymers, Polymer degradation and stability, 59, 145-152 (1998).

16) Auras RA, Lim LT, Selke SE, Tsuji H, Poly (lactic acid): synthesis, structures, properties, processing, and applications, Vol. 10, John Wiley \& Sons (2011).

17) Sheldon RA, Green and sustainable manufacture of chemicals from biomass: state of the art, Green Chemistry, 16, 950-963 (2014).

18) Semba T, Ito A, Kitagawa K, Nakatani T, Yano H, Sato A, Thermoplastic composites of polyamide-12 reinforced by cellulose nanofibers with cationic surface modification, $J$ Applied Polymer Sc, 131 (2014).

19) Fornes TD, Yoon PJ, Keskkula H, Paul DR, Nylon 6 nanocomposites: the effect of matrix molecular weight, Polymer, 42, 9929-9940 (2001). 